\title{
Benign Parotid Gland Neoplasm
}

National Cancer Institute

\section{Source}

National Cancer Institute. Benign Parotid Gland Neoplasm. NCI Thesaurus. Code C4770.

A non-metastasizing neoplasm that arises from the parotid gland. Representative

examples include Warthin tumor, monomorphic adenoma, pleomorphic adenoma, and lipoma. 